\title{
Minireviews
}

\section{Anticancer Activity of Natural and Synthetic Capsaicin Analogs}

\author{
Jamie R. Friedman, ${ }^{1}$ Nicholas A. Nolan, ${ }^{1}$ Kathleen C. Brown, ${ }^{1}$ Sarah L. Miles, \\ Austin T. Akers, Kate W. Colclough, Jessica M. Seidler, John M. Rimoldi, \\ Monica A. Valentovic, and Piyali Dasgupta \\ Department of Biomedical Sciences, Toxicology Research Cluster, Joan C. Edwards School of Medicine, Marshall University, \\ Huntington, West Virginia (J.R.F., N.A.N., S.L.M., K.C.B., A.T.A., K.W.C., J.M.S., M.A.V., P.D.); and Department of Biomolecular \\ Sciences, School of Pharmacy, University of Mississippi, University, Mississippi (J.M.R.)
}

Received June 30, 2017; accepted December 13, 2017

\section{ABSTRACT}

The nutritional compound capsaicin is the major spicy ingredient of chili peppers. Although traditionally associated with analgesic activity, recent studies have shown that capsaicin has profound antineoplastic effects in several types of human cancers. However, the applications of capsaicin as a clinically viable drug are limited by its unpleasant side effects, such as gastric irritation, stomach cramps, and burning sensation. This has led to extensive research focused on the identification and rational design of secondgeneration capsaicin analogs, which possess greater bioactivity than capsaicin. A majority of these natural capsaicinoids and synthetic capsaicin analogs have been studied for their painrelieving activity. Only a few of these capsaicin analogs have been investigated for their anticancer activity in cell culture and animal models. The present review summarizes the current knowledge of the growth-inhibitory activity of natural capsaicinoids and synthetic capsaicin analogs. Future studies that examine the anticancer activity of a greater number of capsaicin analogs represent novel strategies in the treatment of human cancers.

\section{Introduction: Capsaicin}

Capsaicin (trans-8-methyl-N-vanillyl-6-noneamide; Fig. 1A) is the principal, pungent ingredient of chili peppers in the plant genus Capsicum. The compound can be found predominantly within the white pith and membrane of both cayenne and chili peppers (Chapa-Oliver and MejiaTeniente, 2016). It is a potent analgesic and is used topically to treat pain and inflammation associated with a variety of

This work was supported by the MU-WVU Health Partnership award and National Institutes of Health R15 Academic Research Enhancement Award (Grants 1R15CA161491-01A1 and 2R15CA161491-02 to P.D.). A.T.A. and N.A. $\mathrm{N}$. were recipients of a National Aeronautics and Space Administration undergraduate research fellowship from the West Virginia space grant consortium. A.T.A. is also a recipient of the National Science FoundationSummer Undergraduate Research in Engineering summer research fellowship. This work was supported in part by the West Virginia Institutional Development Award Network of Biomedical Research Excellence grant (National Institutes of Health Grant P20GM103434; PI: Dr. G. Rankin), Institutional Development Award, National Institutes of Health National Institute of General Medical Sciences [Grant P20GM104932], and Research Core B of Centers of Biomedical Research Excellence, a component of the National Institutes of Health.

The authors have no financial disclosure or conflict of interest.

${ }^{1}$ J.R.F., N.A.N., and K.C.B. contributed equally to this work as first authors. https://doi.org/10.1124/jpet.117.243691. diseases (O'Neill et al., 2012; Basith et al., 2016). The analgesic activity of capsaicin is mediated by transient receptor potential subfamily vanilloid member 1 receptor (TRPV1), which belongs to the transient receptor potential superfamily of cation-channel receptors (Chen et al., 2014). The transient receptor potential vanilloid receptor family is comprised of six members (TRPV1-6). Capsaicin functions as a classic agonist of the TRPV1 receptor (Caterina et al., 1997). The binding of TRPV1 to capsaicin triggers a plethora of molecular events ultimately inducing to depletion of substance $\mathrm{P}$, desensitization of sensory neurons leading to its analgesic activity. This paved the way for the isolation, design, and synthesis of capsaicin-like compounds (which were TRPV1 agonists) that displayed more potent analgesic activity than capsaicin.

Emerging evidence shows that capsaicin displays anticancer activity in several human cancers, both in cell culture and mice models (for excellent reviews, please refer to (Díaz-Laviada and Rodriguez-Henche, 2014; Basith et al., 2016; Chapa-Oliver and Mejia-Teniente, 2016; Clark and Lee, 2016; Srinivasan, 2016). This led researchers to conjecture that natural and synthetic TRPV1 agonists would display growth-inhibitory effects analogous

ABBREVIATIONS: Bcl-2, B-cell lymphoma-2; CB1, cannabinoid receptor 1; CE, capsaicin epoxide; DHC, dihydrocapsaicin; EVO, evodiamine; MTT, 3-(4,5-dimethylthiazol-2-yl)-2,5-diphenyltetrazolium bromide; N-AVAM, N-acylvanillamide; PhAR, phenylrinvanil; ROPA, resiniferanol-9,13,14 ortho-phenylacetate; ROS, reactive oxygen species; RTX, resiniferatoxin; RUT, rutaecarpine; STAT, signal transducer and activator of transcription; TRPV1, transient receptor potential subfamily vanilloid member 1 receptor; UN-AVAM, unsaturated N-AVAM. 
A

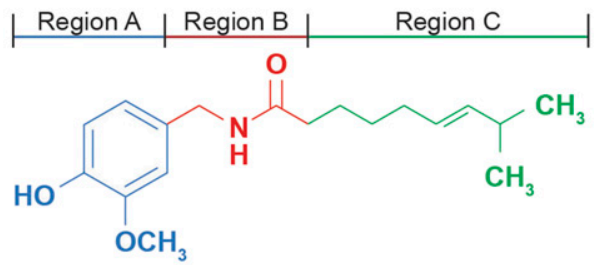

B

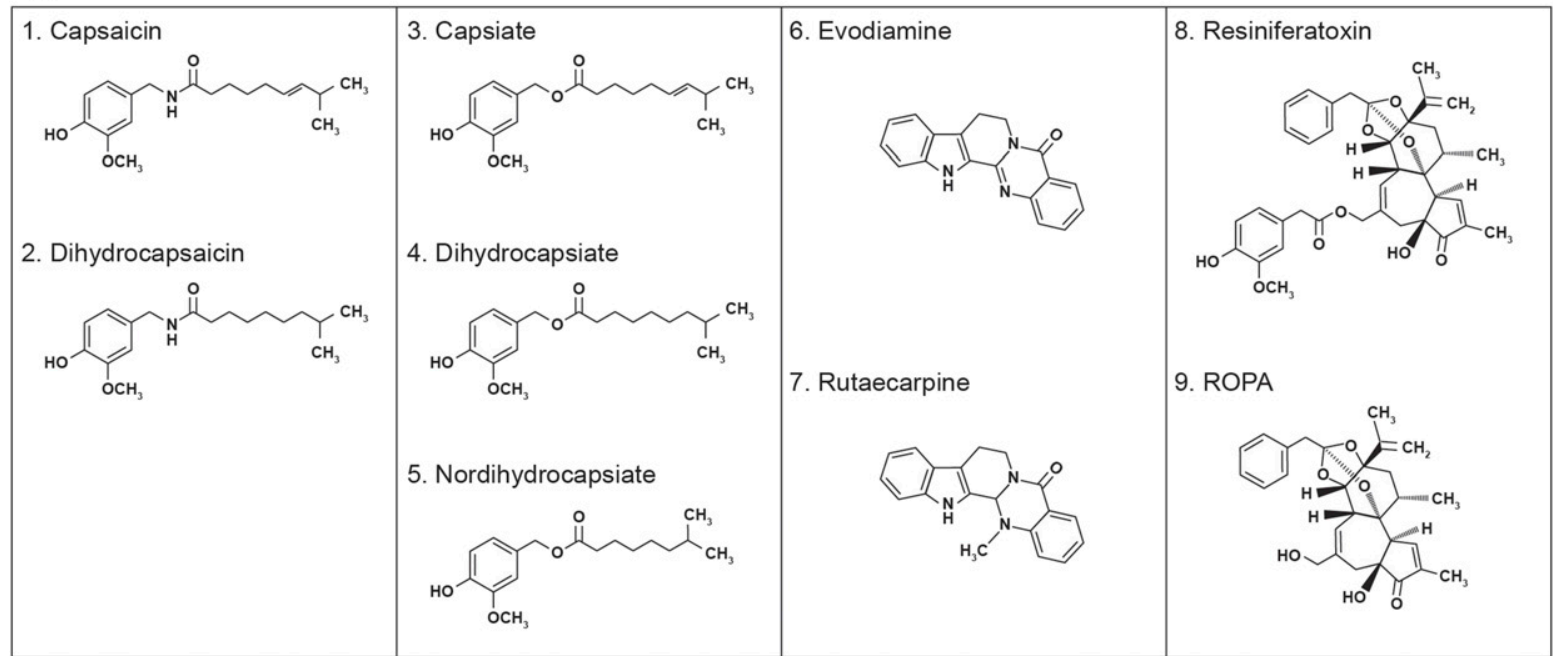

Fig. 1. Structure of natural capsaicinoids. (A) Pharmacophore of capsaicin. The blue structural moiety represents Region A; the red portion of the structure represents Region B; the green alkyl side chain represents Region C. (B) Structure of natural capsaicinoids, which have been investigated for their growth-inhibitory activity in cell culture or animal models.

to capsaicin. Because a large number of TRPV1 agonists (which had been tested for analgesic activity) had already been described in literature, they were initially investigated for their anticancer activity. However, a majority of research studies have shown that the anticancer activity of capsaicin and capsaicin analogs is completely independent of TRPV1 receptor. This is true of both natural capsaicinoids and synthetic capsaicin mimetics (the reader is referred to excellent reviews and papers (Basith et al.; Chapa-Oliver and Mejia-Teniente, 2016; Clark and Lee, 2016; Zigioli et al., 2009)). Although these natural and synthetic capsaicin mimetics are TRPV1 ligands, their anticancer activity does not involve the TRPV1 receptor (Lau et al., 2012). The anticancer activity of capsaicinoids is mediated through the direct interaction of these compounds with key signaling molecules of the cytoplasmic, mitochondrial, and metabolic survival pathways (Díaz-Laviada and Rodriguez-Henche, 2014; Basith et al., 2016; Chapa-Oliver and Mejia-Teniente, 2016; Clark and Lee, 2016; Srinivasan, 2016). The cellular pathways underlying the anticancer activity of capsaicin are not fully understood; however, multiple mechanisms such as increase of intracellular calcium, induction of calpain activity, reactive oxygen species (ROS) generation, inhibition of coenzyme $\mathrm{Q}$, suppression of mitochondrial respiration, and inhibition of transcription factors like p53, signal transducer and activator of transcription (STAT) 3 , and nuclear factor $\kappa \mathrm{B}$ have been shown to be involved (for excellent reviews, see Bode and Dong, 2011; Lau et al., 2012; Clark and Lee, 2016; Fernandes et al., 2016; Cho et al., 2017). In addition to suppressing the growth of human cancer cells, capsaicin promotes the apoptotic activity of cancer chemotherapy agents by multiple mechanisms (Huh et al., 2011; Arzuman et al., 2016; Clark and Lee, 2016; Friedman et al., 2017; Vendrely et al., 2017). For example, capsaicin has been reported to inhibit p-glycoprotein efflux transporters in KB-C2 human endocervical adenocarcinoma cells. The presence of capsaicin in vinblastine-treated $\mathrm{KB}-\mathrm{C} 2$ cells increases the concentration of the vinblastine (Khan et al., 2015b) in the cellular microenvironment and thereby sensitizes these cells to undergo apoptosis. The p-glycoprotein is a well-characterized transmembrane ATPbinding cassette, multidrug resistance 1 transporter involved in efflux of numerous drugs and other xenobiotics (Silva et al., 2015).

The development of capsaicin as a clinically useful drug for pain relief or cancer therapy is hindered by its adverse side effects. The topical or oral administration of capsaicin in humans causes skin redness, hyperalgesia, nausea, intense tearing in the eyes, conjunctivitis, blepharospasm (sustained, forced, involuntary closing of the eyelids), vomiting, abdominal pain, stomach cramps, bronchospasm, and burning diarrhea (Drewes et al., 2003; Hammer, 2006; Evangelista, 2015). Clinical trials exploring the pain-relieving activity of capsaicin have shown that such side effects have resulted in patients discontinuing use of capsaicin due to its strong pungency and nociceptive effect (Drewes et al., 2003; Hammer, 2006; Evangelista, 2015). Such observations have led to research focused on the discovery and design of capsaicin-like compounds, which display greater anticancer activity than capsaicin with a gentler side effect profile. 
Another incentive for the design of capsaicin-based drug candidates is to obtain compounds endowed with improved pharmacological activity, bioavailability, biologic half-life, selectivity, specificity, and therapeutic index relative to capsaicin (Lau et al., 2012). The anticancer activity of capsaicin is covered in several review articles (Khan et al., 2015a; Chapa-Oliver and Mejia-Teniente, 2016; Clark and Lee, 2016). However, the anticancer activity of these natural and synthetic capsaicin-like compounds has yet to be summarized. The present review fills this void of knowledge and discusses the growth-suppressive activity of natural and synthetic capsaicin-like compounds in human cancers. Specifically, the growth-inhibitory activity of these in both tissue culture and animal models will be discussed. We believe that this detailed discussion of the anticancer activity of capsaicin analogs is both timely and relevant, for the potential applications of such compounds in cancer therapy.

\section{Structure Activity Relationship of Capsaicin}

The potential clinical application of capsaicin is restricted by its unfavorable side-effect profile. Clinical studies investigating the analgesic activity of capsaicin have shown that oral capsaicin administration in humans leads to intense abdominal pain, hyperalgesia, stomach cramps, and nausea (O'Neill et al., 2012; Basith et al., 2016). These adverse side effects have caused patients to abandon taking capsaicin. This has led to intense research involving capsaicin structure activity relationship studies to isolate or develop new, less irritating analogs (Drewes et al., 2003; Hammer, 2006; Evangelista, 2015). A second driving force behind the identification and synthesis of capsaicin analogs is that of novel drug discovery that aims to generate new capsaicin mimetics with better pharmacological and therapeutic profile than the parent molecule. The structure of capsaicin can be broken down into three major areas, which are depicted in Fig. 1A. The three major regions are as follows: aromatic (Region A), amide (Region B), and the hydrophobic (Region C). (Huang et al., 2013; Diaz-Laviada and Rodriguez-Henche, 2014; Basith et al., 2016; ChapaOliver and Mejia-Teniente, 2016; Clark and Lee, 2016; Srinivasan, 2016).

\section{Antineoplastic Activity of Natural Capsaicin Analogs}

Capsiates. Data from several independent research laboratories have led to the discovery of natural capsaicin-like compounds that resemble the structure of capsaicin but contain variations in Regions A (aromatic), B (amide), or C (hydrophobic). There are few published reports about natural capsaicin-like compounds (capsaicinoids) that have alterations in Region A (Ogasawara et al., 2002; Gavaraskar et al., 2015). However, several capsaicinoids having variations in Region B have been reported to suppress the growth of human cancer cells in cell culture. The nonpungent capsaicinoid, capsiate (Fig. 1B3), is isolated from a strain of peppers called CH-19 Sweet. Apart from capsiate, CH-19 Sweet is also the source for two additional capsiate-like compounds, namely dihydrocapsiate and nordihydrocapsiate (Fig. 1, B4 and B5) (Macho et al., 2003; Watanabe et al., 2011). These three compounds differ from capsaicin in Region B; dihydrocapsiate and nordihydrocapsiate contain an ester bond instead of an amide bond between the vanillyl motif and the fatty acid side chain. Dihydrocapsiate and nordihydrocapsiate also differ in Region C relative to capsaicin. Dihydrocapsiate and nordihydrocapsiate have only saturated bonds in the alkyl chain of Region C instead of a single double bond observed in capsaicin. Macho et al. (2003) studied the antiapoptotic activity of capsiate, dihydrocapsiate, and nordihydrocapsiate in Jurkat human acute T-cell leukemia cells. They observed that all three compounds induced apoptosis in a concentration-dependent manner when incubated with Jurkat cells.

Several convergent studies have indicated that capsaicin may also function as a tumor promotor in skin cancer, breast cancer, and colon cancer (Bode and Dong, 2011). In contrast, all capsaicin-like compounds (natural capsaicinoids or synthetic capsaicin mimetics) have shown only growth-inhibitory activity toward numerous cell lines (Basith et al., 2016). Nordihydrocapsiate further showed potent chemopreventive activity in an in vivo two-stage model of mouse skin carcinogenesis. These findings would suggest that, in this experimental model and with application of a promotor, nordihydrocapsiate may provide protection against skin cancer (Macho et al., 2003). The mechanism of action of these capsiates was similar to capsaicin and was mediated by inhibition of transcription factor nuclear factor $\kappa \mathrm{B}$, elevation of reactive oxygen species, and loss of mitochondrial membrane potential (Fig. 2A) (Macho et al., 2003; Watanabe et al., 2011). Most interestingly, nordihydrocapsiate showed better proapoptotic activity than capsaicin in Jurkat cells, as reflected by the $\mathrm{IC}_{50}$ values (nordihydrocapsiate, $\mathrm{IC}_{50}=$ $75 \mu \mathrm{M}$; capsaicin, $\left.\mathrm{IC}_{50}=125 \mu \mathrm{M}\right)$ (Macho et al., 2003). Both capsiate and dihydrocapsiate displayed antiangiogenic activity in cell culture and mouse models (Fig. 2A). These compounds suppressed vascular endothelial growth factor-induced angiogenesis in human umbilical cord endothelial cells via direct suppression of Src kinase activity and phosphorylation of its downstream substrates, such as $\mathrm{p} 125^{\mathrm{FAK}}$ and vascular endothelial cadherin. Most interestingly, capsiate and nordihydrocapsiate do not affect autophosphorylation of the vascular endothelial growth factor receptor kinase insert domain/fetal liver kinase (Min et al., 2004; Pyun et al., 2008). The antiangiogenic activities of the two compounds were comparable to each other and to capsaicin. Such nonpungent capsaicinoids (capsiate and its related compounds) may be more applicable in cancer therapy than capsaicin.

Evodiamine and Rutaecarpine. Evodiamine (EVO; Fig. 1B6) and rutaecarpine (RUT; Fig. 1B7) are alkaloids isolated from the fruit of the Chinese medical plant Evodia rutaecapra, otherwise known as Evodia fruit (Yu et al., 2013; Wu et al., 2016, 2017). Capsaicin and EVO share pharmacophore elements, but their lipophilic moiety (Region C) is different, encompassing a saturated isononenyl unsaturated group in capsaicin, and two phenyl rings in evodiamine (Pearce et al., 2004; Wang et al., 2009, 2015; De Petrocellis et al., 2014). Wang et al. $(2012,2015)$ have performed docking and molecular modeling on the pharmacophore of EVO and capsaicin and observed a remarkable similarity between the pharmacophore of the two compounds (Wang et al., 2012, 2015). EVO has been characterized as a potent, selective agonist of the TRPV1 receptor, similar to capsaicin (Ivanova and Spiteller, 2014; Wang et al., 2016). Cell culture studies show that EVO 

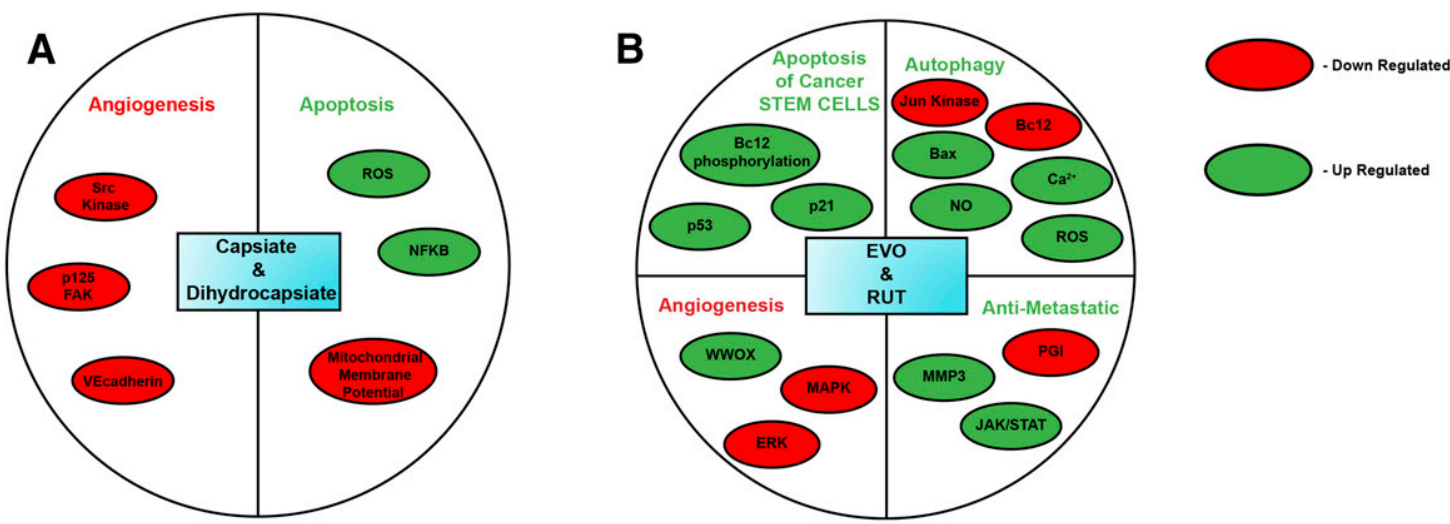

Fig. 2. Signaling pathways underlying the anticancer activity of natural capsaicinoids. (A) Capsiate and dihydrocapsiate, (B) EVO and RUT.

displays growth-inhibitory activity in human breast cancer, prostate cancer, leukemia, urothelial cell carcinoma, gastric cancer, osteosarcoma, oral cancer, nonsmall lung cancer, colon cancer, glioma, glioblastoma, thyroid cancer, melanoma, and cervical cancer cells (Lee et al., 2006; Kan et al., 2007; Chen et al., 2010; Du et al., 2013; Fang et al., 2014; Gavaraskar et al., 2015; Huang et al., 2015; Khan et al., 2015a; Sachita et al., 2015; Shen et al., 2015; Hu et al., 2016; Shi et al., 2017; Wu et al., 2017; Yang et al., 2017). However, EVO has been shown to be an antagonist of the aryl hydrocarbon receptor as well ( $\mathrm{Yu}$ et al., 2010). The growth-suppressive activity of EVO is mediated by cell cycle arrest, apoptosis, and autophagy, which involve a symphony of mechanisms (Fig. 2B), including downregulation of survivin, Akt, STAT3, Mcl-1, B-cell lymphoma-2 (Bcl-2) and cdc-p15, and upregulation of caspase-3, phosphatase and tensin homolog, Bcl-2 associated killer, Bax, Fas ligand, microRNA-429, matrix metalloproteinase-9, Jun kinase, cyclin B1, cdc25c, and cdc2p161 (Lee et al., 2006; Zhu et al., 2011; Fang et al., 2014; Huang et al., 2015; Khan et al., 2015a; Meng et al., 2015; Peng et al., 2015; Zou et al., 2015; Chen et al., 2016; Han et al., 2016; Li et al., 2016; Liu et al., 2016; Wei et al., 2016; Fan et al., 2017; Wu et al., 2017; Yang et al., 2017). EVO-induced autophagy in human glioblastoma cells is mediated by Jun kinase, Bcl-2, and elevation of Bax, intracellular calcium, and induction of ROS/nitric oxide (Liu et al., 2013a,b). The antitumor activity of EVO has been explored in athymic mouse models of human hepatocellular carcinoma, colon cancer, and renal carcinoma (Zhang et al., 2010; Yang et al., 2013; Wu et al., 2016). The anticancer activity of EVO in hepatocellular cancer (Fig. 2B) may be attributed to its ability to suppress $\beta$-catenin-mediated angiogenesis (Shi et al., 2016). In contrast, EVO suppressed the growth of human renal carcinoma cells in vivo by inducing phosphorylation of Bcl2 (Wu et al., 2016). In addition, EVO targeted breast cancer stem-like cells by activating p53 and p21 expression (Han et al., 2016). In gastric cancer stem cells, EVO inhibited proliferation via inhibition of the Wingless/ $\beta$-catenin pathway (Wen et al., 2015).

EVO has been shown to induce apoptosis in drug-resistant human cancer cells. EVO displays antiproliferative activity in camptothecin-resistant human leukemia cells (Pan et al., 2012). The mechanism of EVO-induced $\mathrm{G}_{2} / \mathrm{M}$ arrest involves the inhibition of topoisomerase 1 and 2 (Lee et al., 2015).
Similarly, EVO induces cell cycle arrest in Taxol-resistant ovarian cancer cells and in Adriamycin-resistant human breast cancer cells (Liao et al., 2005; Zhong et al., 2015). EVO triggers apoptosis in human colon cancer cells resistant to oxaliplatin and cisplatin (Ogasawara et al., 2001; Wen et al., 2015). EVO sensitizes human cancer cells to the apoptotic effects of chemotherapeutic agents. EVO synergizes with doxorubicin and gemcitabine to produce increased apoptosis in breast cancer and pancreatic cancer cells, respectively (Wei et al., 2012; Wang et al., 2014). Likewise, EVO enhances the efficacy of erlotinib in human lung cancer and in human ovarian cancers ( $\mathrm{Li}$ et al., 2016). Moreover, EVO sensitizes U87MG human glioblastoma cells to the proapoptotic effects of tumor necrosis factor-related apoptosis-inducing ligand. $\mathrm{Hu}$ et al. (2016) observed that EVO sensitizes human gastric cancer cells to the growth-suppressive effects of radiotherapy in vitro and in vivo (Hu et al., 2016). In addition to promoting apoptosis in various cancer cells, EVO alters the ATP-binding cassette subfamily $\mathrm{G}$ member 2 breast cancer-resistant protein transporter to increase chemosensitivity of colorectal cancer cells. EVO was not a substrate inhibitor of ABCG2, as EVO diminished ABCG2 protein expression in HCT-116/LOHP cells, which increased cancer chemosensitivity to cisplatin (Sui et al., 2016). Additional studies are needed to explore whether EVO can modify ABCG2 protein expression in other cancer cells.

EVO displays antimigratory, anti-invasive, and antimetastatic activity in human lung cancer, breast cancer, and nasopharyngeal cancer cells in vitro and in mouse models. EVO exerts antimetastatic activity by multiple mechanisms, such as regulation of matrix metalloproteinase- 3 activity, p38 kinase activity, extracellular signal-regulated kinase activity, and Janus kinase/STAT pathway, and downregulation of phosphoglucose isomerase (Du et al., 2013; Peng et al., 2015; Zhao et al., 2015).

RUT is the second major alkaloid isolated from $E$. rutaecapra. It is a potent agonist of TRPV1 (Ivanova and Spiteller, 2014). RUT displayed antiproliferative activity in threedimensional spheroid models of human breast cancer cells (Guo et al., 2016). The antineoplastic activity of EVO and RUT has led to intense research involving design and synthesis of second-generation EVO-like or RUT-like analogs with improved anticancer activity (Fig. 2B). The reader is referred to some excellent reviews on this subject (Hong et al., 2010; 
Li-Weber, 2013; Song et al., 2013; Yu et al., 2013). Further studies are needed to investigate whether TRPV1 signaling pathway plays a role in the anticancer activity of EVO and Rut.

Resiniferatoxin. The capsaicin analog resiniferatoxin (RTX; Fig. 1B8) is a tricyclic diterpene isolated from the latex of the cactus plant Euphorbia resinifera (Iadarola and Gonnella, 2013). RTX is one of the most potent TRPV1 agonists ever described in literature (Brown, 2016). As can be seen in the figure above, the structure of capsaicin and RTX closely resembles each other, except that Region $\mathrm{C}$ is a diterpene moiety of the daphnane class (Carnevale and Rohacs, 2016). Furthermore, pharmacophore clustering and docking studies reveal a close similarity between the two compounds (Hartel et al., 2006; Athanasiou et al., 2007; Carnevale and Rohacs, 2016; Elokely et al., 2016; Lee et al., 2016). Based on previous studies, four sites represent the pharmacophore of RTX, as follows: 1) 4-hydroxy-3-methoxyphenyl, 2) C20 ester, 3) C3keto, and 4) orthophenyl groups (Huang et al., 2013). The growth-inhibitory activity of RTX has been investigated in multiple human cancer cells. Of these, RTX caused robust apoptosis in human bladder cancer cell lines (T24, 5637) and in athymic mouse models xenografted with T24 bladder cancer cells (Farfariello et al., 2014). However, it did not trigger cell death in normal human urothelial cells. This observation is interesting because RTX selectively targeted human bladder cancer cells, but not the normal urothelial cells.

RTX mimics capsaicin-producing selective apoptosis for human cancer cells while sparing the normal cells (Lau et al., 2014). However, RTX differs by inducing prolonged cell cycle arrest (within $G_{0}$ phase) in IEC-18 rat ileal epithelial cells. Such differences can be explained by the fact that the IEC-18 is an immature epithelial cell line derived from rat intestinal crypt, and therefore its growth characteristics cannot be compared with normal primary adult epithelial cells (Frey et al., 2004). Additionally, species-specific differences between rat and human cell lines may explain the varying response of RTX between IEC-18 and normal urothelial cells. In agreement with other studies, the growth-suppressive effects of RTX were found to be independent of TRPV1 receptor and involved a decrease of cyclin D1 at mRNA and protein levels (Frey et al., 2004).
The compound resiniferanol-9, 13, 14 ortho-phenylacetate (ROPA) is a hydrolysis product of RTX (Fig. 1B9). Frey et al. (2004) investigated the growth-inhibitory activity of ROPA on IEC-18 cells (Frey et al., 2004). ROPA was found to induce a transient protein kinase $\mathrm{C}-$ dependent cell cycle arrest in $\mathrm{G}_{1}$ phase. The cell cycle-inhibitory effects of ROPA were accompanied by a decrease in cyclin D1 levels and simultaneous upregulation of p21 expression (Fig. 3A) (Frey et al., 2004). In contrast, RTX did not have any effect on p21 levels in IEC-18 cells. A remarkable observation was that the growthinhibitory activity of ROPA as well was found to be independent of the TRPV1 receptor family (Frey et al., 2004). The apoptotic activity of RTX was mediated by diverse mechanisms (Fig. 3A) such as mitochondrial depolarization, generation of reactive oxygen species, suppression of mitochondrial respiration, blockage of protein kinase $\mathrm{C}$, inhibition of cyclin D1, and induction of p21 ${ }^{\text {waf1/Cip1 }}$ (Hartel et al., 2006; Athanasiou et al., 2007; Ziglioli et al., 2009; Farfariello et al., 2014; Vercelli et al., 2014).

Dihydrocapsaicin. The capsaicin analog dihydrocapsaicin (DHC) differs from capsaicin in the hydrophobic Region C. It contains a saturated bond between $\mathrm{C} 6$ and $\mathrm{C} 7$ carbon atoms of Region C (Fig. 1B2). DHC is less pungent than capsaicin based on the Scoville heat unites. The anticancer activity of DHC has been observed in several human cancer cell lines, including human breast cancer cells, colon cancer cells, and gliomas (Oh et al., 2008; Oh and Lim, 2009). A majority of these studies have been done in cell culture. An intriguing observation was that DHC showed greater growth-inhibitory activity than capsaicin in these cell lines. The growth-inhibitory effects of DHC (Fig. 3B) were mediated via cell cycle arrest, apoptosis, and autophagy inhibition of cellular metabolism (Oh et al., 2008; Halme et al., 2016). The antitumor activity of DHC was observed in athymic mouse models of human gliomas as well (Xie et al., 2016). However, the drawback with DHC is that it has pungent and irritant properties like capsaicin (Schneider et al., 2014).

\section{Antineoplastic Activity of Synthetic Capsaicin Analogs}

N-Acylvanillamides. Among all synthetic analogs of capsaicin, the $\mathrm{N}$-acylvanillamides (N-AVAMs) are of the most extensively researched for their analgesic activity (Melck et al., 1999; Kobata et al., 2010; Huang et al., 2013).
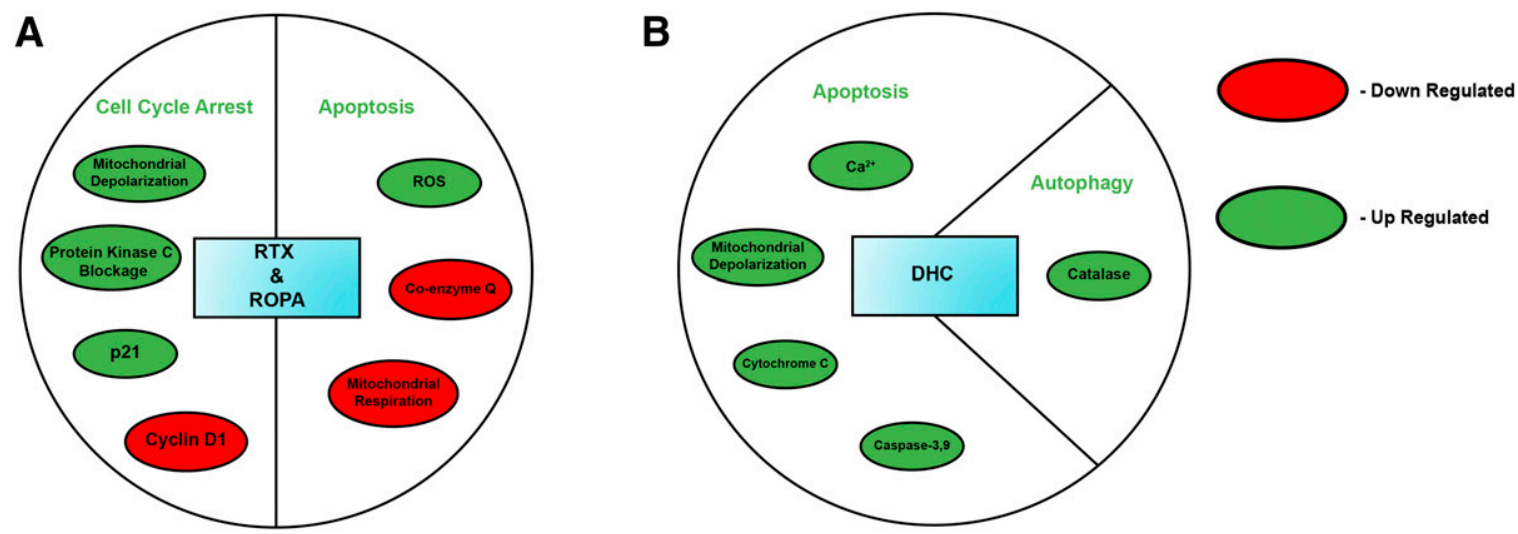

Fig. 3. Signal transduction pathways mediating the antitumor activity of natural capsaicinoids. (A) RTX and ROPA, (B) DHC. 
A Dohevanil [C22:6]<smiles>CC/C=C\C/C=C\C/C=C\C/C=C\C/C=C\C/C=C\CC(=O)NCc1ccc(O)c(OC)c1</smiles>

C Rinvanil [C18:1]<smiles>CCCCCCCCCCCCC(=O)NCc1ccc(O)c(OC)c1</smiles>

B Olvanil [C18:1]<smiles>CCCCCCCCCCCCCC(=O)NCc1ccc(O)c(OC)c1</smiles>

D Phenylacetylrinvanil (PhAR) [C18:1]<smiles>CCCCCCCCCCCC(=O)NCc1ccc(O)c(OC)c1</smiles>

E Arvanil [C20:4]<smiles>CCCCC/C=C\C/C=C\C/C=C\C/C=C\CCC(=O)NCc1ccc(O)c(OC)c1</smiles>

Fig. 4. A panel of UN-AVAMs that have been investigated for their growth-suppressive activity in cell culture or mice models. (A) Dohevanil. The first number in the rectangular brackets indicates the chain length, and the number after the colon indicates the number of double bonds. For example: [C22: 6] written next to dohevanil means dohevanil has a chain length of 20 carbon atoms and 6 double bonds in this alkyl side chain. (B) Olvanil [C18:1]. (C) Rinvanil [C18:1]. (D) Phenylacetylrinvanil (PhAR) [C18:1]. (E) Arvanil [C20:4].

There are numerous studies that have investigated their anticancer activities in diverse human cancer cell lines (Sancho et al., 2003; Stock et al., 2012; Sánchez-Sánchez et al., 2015). This class of compounds is modified in the hydrophobic Region C of capsaicin (Fig. 4). Early studies experimented with substituting the acyl side chain with saturated long-chain lipophilic groups. However, these compounds were inactive (Melck et al., 1999). The introduction of long-chain unsaturated fatty acids fully restored the analgesic activity of these compounds. The N-AVAMs are nonpungent and do not have the unfavorable side effects of capsaicin. Structure activity studies experimented with the magnitude of unsaturation in these side chain and the length of the side chain to yield capsaicin analogs with improved analgesic activity and binding profile to TRPV1 (Huang et al., 2013). Recent studies examined the growthinhibitory activity of these unsaturated N-AVAMs (UNAVAMs). Tuoya et al. (2006) demonstrated that the UN-AVAM dohevanil (Fig. 4A) induced a greater magnitude apoptosis in MCF-7 human breast cancer cells than capsaicin in vitro (Tuoya et al., 2006). Appendino et al. (2005) synthesized a panel of UN-AVAM compounds with varying affinity for human TRPV1 receptor (Appendino et al., 2002, 2005). Of these compounds, several studies have investigated the growth-inhibitory activity of olvanil (Fig. 4B), rinvanil (Fig. 4C), and phenylacetylrinvanil (PhAR) (Fig. 4D). The 3-(4,5-dimethylthiazol-2-yl)-2,5-diphenyltetrazolium bromide (MTT) assays showed that olvanil decreased the viability of $\mathrm{C} 6$ rat glioma cells and EFM-19 breast cancer cells (Melck et al., 1999; Huang et al., 2013) (Fig. 5). Apart from being a potent TRPV1 agonist, these compounds displayed weak binding and activation of cannabinoid receptor 1 (CB1) and competitively inhibited the anandamide membrane transporter. Luviano et al. (2014) studied the growth-inhibitory activity of rinvanil and PhAR in J774, P388, and WEHI-3 mouse leukemic cell lines (Fig. 5). PhAR showed improved growth-inhibitory activity relative to rinvanil and capsaicin in all of the cell lines studied (Luviano et al., 2014). Additionally, PhAR displayed some selectivity for leukemic cell lines relative to normal mouse bone marrow cells (Luviano et al., 2014). However, contradictory findings were found later by Sánchez-Sánchez et al. (2015), who analyzed the antiproliferative and cytotoxic activity in a panel of human cervical cancer cell lines, namely HeLa, CaSki, and ViBo. The growth-inhibitory activity of these compounds varied from cell line to cell line and did not correlate with their binding profile to human TRPV1 receptor (Sánchez-Sánchez et al., 2015). The researchers also observed that rinvanil showed selective growth-inhibitory effects on the cervical cancer cells relative to normal lymphocytes, whereas PhAR showed no selectivity between normal and tumor cells (Sánchez-Sánchez et al., 2015). Such variance in results may be attributed to the nature of the cancer, species-specific differences (human cell lines versus mouse cell lines) and the disparity in the methodology used in the two studies. Whereas the studies 

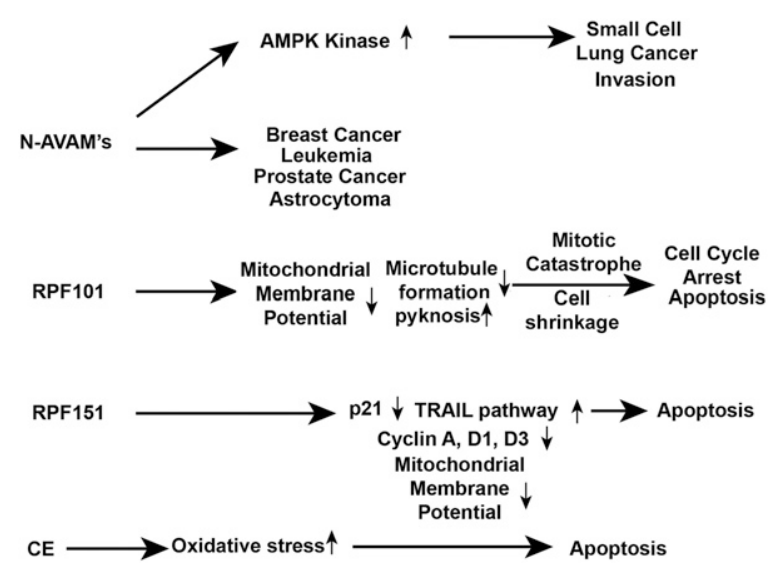

Fig. 5. Signaling pathways underlying the antiproliferative and proapoptotic activity of synthetic capsaicin analogs.

performed by Luviano et al. (2014) studied the growthinhibitory effects of PhAR and rinvanil by the Sulforhodamine B assay, Sánchez-Sánchez et al. (2015) used the lactate dehydrogenase assay to evaluate the effect of PhAR and rinvanil on normal lymphocytes (Luviano et al., 2014; Sánchez-Sánchez et al., 2015).

Di Marzo et al. (2002) developed arvanil, an extremely powerful TRPV1 agonist (Fig. 4E). Arvanil is a very potent agonist of the TRPV1 and CB1 receptor (Di Marzo et al., 2002). It also induces robust inhibition of anandamide membrane transporter and fatty acid amide hydroxylase (Melck et al., 1999; De Petrocellis et al., 2000; Di Marzo et al., 2002; Glaser et al., 2003). Experiments in cell culture systems showed that arvanil suppressed the growth of C6 mouse glioma cells (De Lago et al., 2006), Jurkat human T-cell leukemia cells (Sancho et al., 2003), human breast cancer cells (MCF-7, T-47D, and EFM-19 cell lines), and prostate cancer cells (DU145, PPC-1, and TSU cell lines) (Fig. 5) (Melck et al., 1999; Di Marzo et al., 2000; Li and Moore, 2014). A majority of these studies showed that the growth-suppressive activity of arvanil was independent of TRPV1 and CB1 receptor (Melck et al., 1999). Stock et al. (2012) investigated the antineoplastic activity of arvanil in HG-astrocytoma cells organotypically grown in mouse brain slices (Fig. 5). Arvanil suppressed the growth of HG-astrocytoma at a relatively low concentration of $50 \mathrm{nM}$ (Stock et al., 2012). Subsequently, Stock et al. (2012) confirmed the antineoplastic activity of arvanil in HG-astrocytoma tumors implanted in immunocompromised severe combined immunodeficiency mice. They observed that arvanil suppressed the tumor growth rate of HG astrocytomas better than temozolomide (the standard of care for astrocytoma patients). The survival time of mice administered with arvanil was greater than vehicletreated mice (Stock et al., 2012). This study administered a combination of arvanil and temozolomide, which showed an increase in survival times compared with either agent administered alone or mice administered with vehicle only (Stock et al., 2012). Stock et al. (2012) observed that the anticancer activity of arvanil in human astrocytomas was de pendent on the TRPV1 receptor only (Stock et al., 2012). These results are divergent from those found in human breast and prostate cancer cells (Melck et al., 1999). Such different observations may be due to differences in the cell biology of neuronal and non-neuronal human cancer cells. Small cell lung cancer is a neuroendocrine tumor characterized by rapid doubling time, aggressive clinical course, and a dismal 5-year survival rate. The N-AVAMs arvanil and olvanil suppressed the invasion of human small cell lung cancer cell lines via the $5^{\prime}$ AMP-activated protein kinase pathway (Hurley et al., 2017).

RPF, Epoxide-Based Analogs. de-Sá-Júnior et al. (2013) synthesized a capsaicin mimetic called RPF101 (Fig. 6A). The structure of RPF101 differs from capsaicin, primarily in Region B, where the amide group has been replaced by a bioisosteric sulfonamide (de-Sá-Júnior et al., 2013). The alkyl side chain in Region $\mathrm{C}$ was replaced with a benzene moiety. The antiproliferative and apoptotic activity of RPF101 in MCF-7 human breast cancer was greater than capsaicin. RPF101 caused cell shrinkage and pyknosis (Fig. 5) in threedimensional spheroid cultures of MCF-7 cells (de-Sá-Júnior et al., 2013). RPF101 caused a disruption of mitochondrial membrane potential, dysregulation of microtubule formation, and mitotic catastrophe to induce cell cycle arrest and apoptosis in human breast cancer cells (Fig. 5) (de-SáJúnior et al., 2013). The research group further modified RPF101 to produce an analog RPF151 (Fig. 6B) with better stability and aqueous solubility properties (Ferreira et al., 2015). In addition, RPF151 displayed lower hyperalgesia relative to capsaicin. MTT assays showed that RPF151 decreased cell viability better than capsaicin in MDA-MB-231 human breast cancer cells. However, RPF151 did not differentiate between MCF-10A normal human breast epithelial cells and breast cancer cells (Ferreira et al., 2015). The mechanism of action of RPF151 was divergent from RPF101. RPF151 induced cell cycle arrest at S-phase with concomitant decrease in cyclin A, D1, and D3 (Fig. 5). RPF151 also induced apoptosis in MDA-MB-231 cells via downregulation of $\mathrm{p} 21$, reduction of mitochondrial membrane potential, and activation of the tumor necrosis factor-related apoptosis-inducing ligand pathway (Ferreira et al., 2015). The antineoplastic activity of RPF151 was analyzed by nude mice model of human breast cancer, where it showed higher antitumor activity than capsaicin. Most remarkably, the growthsuppressive activity of RPF151 is independent of the TRPV1 receptor.

Lewinska et al. (2015) synthesized a constrained capsaicin analog that contained an epoxide motif in Region $\mathrm{C}$ of the capsaicin (Fig. 6C). The growth-suppressive activity of capsaicin epoxide (CE) compared with capsaicin was studied in a diverse array of cell lines using the MTT assay (Lewinska et al., 2015). Both capsaicin and CE did not reduce the viability of human dermal fibroblasts. However, CE decreased the viability of NIH/3T3 murine embryonic fibroblasts better than capsaicin (Lewinska et al., 2015). The varying results in this study could be due to species and lineage differences between human dermal fibroblasts and the NIH/3T3 cells. Similarly, the growth-inhibitory activity of $\mathrm{CE}$ was found to be better than capsaicin in prostate cancer, breast cancer, cervical cancer, and renal cancer cell lines. The human breast cancer cell line MCF-7 was found to be most responsive to CE-induced cell death (Lewinska et al., 2015). CE was shown to trigger robust apoptosis in these cell lines by inducing oxidative stress (Fig. 5). 


\section{A RPF101}<smiles>O=S(=O)(NCc1ccc2c(c1)OCO2)c1ccccc1</smiles>

B RPF151<smiles>CCCCS(=O)(=O)NCc1ccc2c(c1)OCO2</smiles>

\section{Capsaicin Epoxide}

Fig. 6. Capsaicin analogs containing a sulfonamide and epoxide motif in their structure trigger apoptosis in human cancer cells. (A) RPF101. (B) RPF151. (C) Capsaicin epoxide.<smiles>COc1cc(CNC(=O)CCCCC2OC2C)ccc1O</smiles>

Miscellaneous Capsaicin Analogs. The TRPV1 antagonist capsazepine (Fig. 7A) displayed potent antitumor activity in human prostate cancer and osteosarcoma cells (Teng et al., 2004; Huang et al., 2006; Lee et al., 2017). Gonzales et al. (2014) showed that capsazepine suppressed the growth of human oral squamous cell carcinoma in cell culture and xenograft models in athymic mice. The apoptotic activity of capsaicin was found to be independent of TRPV1 (Huang et al., 2006). The apoptotic activity of capsazepine was induced by endoplasmic reticulum stress, increase of ROS, followed by increase of intracellular calcium in a phospholipase C-independent pathway (Fig. 8). Capsazepine was also found to be an inhibitor of Janus kinase/STAT3 signaling in prostate cancer cells (Huang et al., 2006). Capsazepine also sensitized A549 lung cancer cells to radiation therapy (Nishino et al., 2016). Thomas et al. (2007, 2011, 2012) synthesized the capsaicin analog nonivamide (Fig. 7B), which decreased the viability of the immortalized human lung epithelial cell line BEAS-2B overexpressing TRPV1 (referred in this work as TRPV1-OE cells) (Thomas et al., 2007, 2011, 2012). Nonivamide and its analog N-(3,4-dihydroxybenzyl)nonamide (Fig. 7C) displayed potent growth-suppressive activity in TRPV1-OE cells, and this process was mediated by the ROS oxidative stress pathway (Thomas et al., 2007). Damião et al. (2014) synthesized a variety of capsaicin analogs (Fig. 7, C-E) and tested for their cytotoxicity in B16F10 (mouse melanoma), SK-MEL-28 (human melanoma), NCI-H1299, NCI-H460 (human lung cancer), SK-BR-3, and MDA-MB-231 (human breast cancers) cell lines (Damião et al., 2014). The capsaicin analog $\mathrm{N}$-(benzo[d] [1,3]dioxol-5-ylmethyl)-4-methoxybenzamide (Fig. 7D) decreased the viability of human NCI-H1299 cells and mouse melanoma cells, comparable to capsaicin. Benzo[d][1,3]dioxol-5-ylmethyl hexanoate (Fig. 7E) showed greater growth-inhibitory activity in SK-MEL-28 cells than capsaicin (Damião et al., 2014), whereas its growth-suppressive effects are similar to capsaicin in mouse melanoma cells. Furthermore, the authors performed exploratory data analysis and molecular modeling on these both, $\mathrm{N}$-(benzo[d][1,3]dioxol-5-ylmethyl)-4-methoxybenzamide and benzo[d][1,3]dioxol-5-ylmethyl hexanoate. These in silico experiments suggested that aryl amides, esters, and alkyl esters may be promising scaffolds to develop capsaicin mimetics with improved anticancer activity (Damiao et al., 2014). The compound MRS1477 (Fig. 7F), a positive allosteric modulator of TRPV1, was found to be very robust in inducing apoptosis in human breast cancer cells in vitro and in athymic mouse model (Naziroğlu et al., 2017). The growth-inhibitory effects of MRS1477 were observed at fivefold lower concentration relative to capsaicin. The proapoptotic activity of MRS1477 was mediated by the TRPV1 receptor (Naziroglu et al., 2017).

\section{Conclusions and Future Directions}

The nutritional compound capsaicin has shown potent anticancer activity in multiple human cancers. However, the therapeutic potential of capsaicin has been limited by its unpleasant side effects. This has led to intense research focused on the discovery and design of natural and synthetic capsaicin-like compounds. A variety of natural capsaicinoids has been isolated from peppers and other natural sources. Similarly, synthetic capsaicin analogs have been designed by manipulating the pharmacophore of capsaicin. Another aim of the rational design of capsaicin analogs has been to find compounds that will display better bioactivity and greater therapeutic index. A promising class of synthetic nonpungent capsaicin mimetics are long-chain unsaturated N-AVAMs. An exciting development in the field of capsaicin analogs has been the synthesis of allosteric TRPV1 modulators for cancer therapy. However, a majority of these capsaicin mimetics have been tested for their analgesic activity and not their anticancer activity. The growth-inhibitory activity of some capsaicin analogs has been predominantly analyzed in cell culture and not in animal models. Such data underline the importance of examining the antineoplastic of different types of synthetic capsaicin mimetics in athymic mouse and patientderived xenograft models. Capsaicin, capsiate, and EVO have 
<smiles>Oc1cc2c(cc1O)CN(C(=S)NCCc1ccc(Cl)cc1)CCC2</smiles>

\section{B Nonivamide}<smiles>CCCCCCCCCC(=O)NCc1ccc(O)c(OC)c1</smiles>

C N-(3,4-dihydroxybenzyl)nonanamide

D $\mathrm{N}-\mathrm{BMB}$<smiles>CCCCCCCCC(=O)NCc1ccc(O)c(O)c1</smiles><smiles>COc1cccc(C(=O)NCc2ccc3c(c2)OCO3)c1</smiles>

E $\mathrm{BMH}$

F MRS 1477<smiles>CCCCCCCCCCC(=O)OCc1ccc2c(c1)OCO2</smiles><smiles>CCOC(=O)C1=C(c2ccccc2)NC(C)=C(C(=O)SCCOC)C1CC</smiles>

Fig. 7. Miscellaneous capsaicin analogs that display growth-inhibitory activity in human and mouse cancer cell lines. (A) Capsazepine, a TRPV1 antagonist. (B) Nonivamide. (C) N-(3-4 dihydroxy) nonivamide. (D) N-(Benzo[d][1,3]dioxol-5-ylmethyl)-4-methoxybenzamide (N-BMB). (E) Benzo[d] [1,3]dioxol-5yl-methyl hexanoate (BMH). (F) MRS1477.

been shown to display potent antiangiogenic activity in both cell culture and mouse models. In contrast, there are no reports of the antiangiogenic activity of other natural and synthetic capsaicin analogs. Another promising area of research is the combinatorial anticancer activity of these capsaicin analogs with conventional chemotherapy or radiation. The development of nonpungent second-generation capsaicin mimetics with anticancer and antiangiogenic activity will pave the way for novel treatment regimens in human cancers.

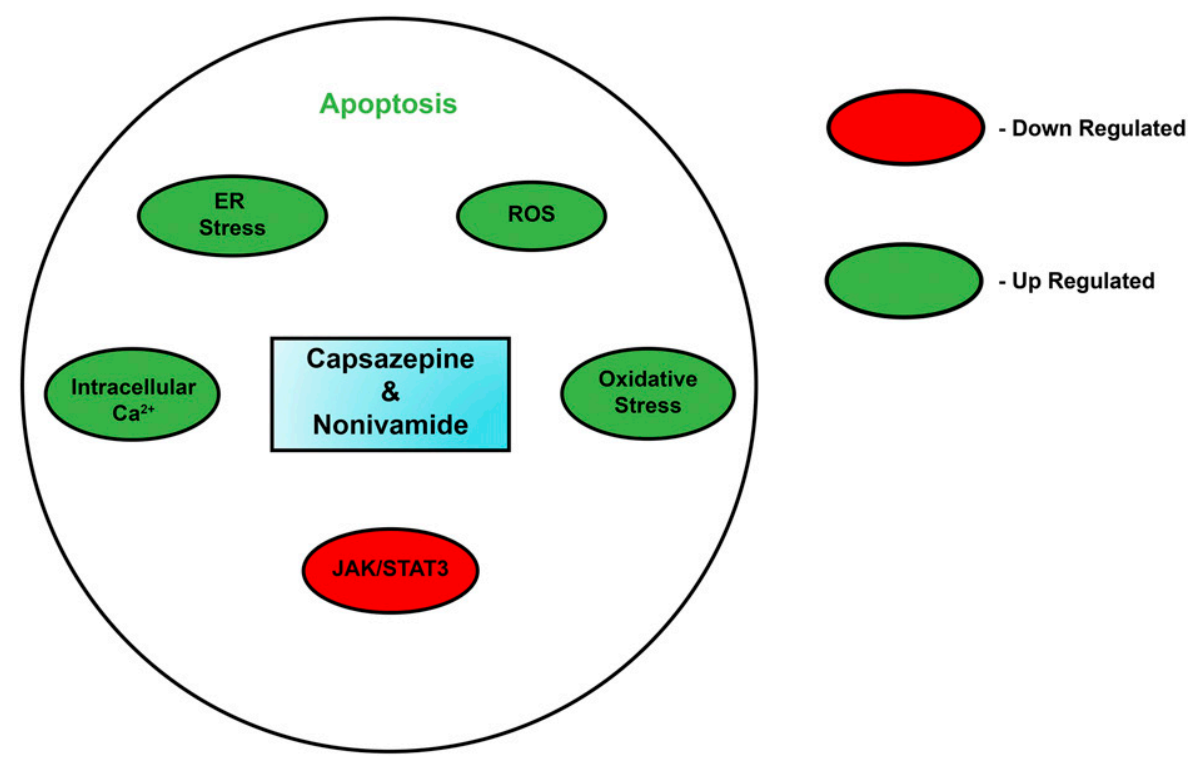

Fig. 8. Molecular mechanisms underlying the apoptotic activity of capsazepine and nonivamide. 


\section{Acknowledgments}

The authors thank Dr. Srikumar Chellappan and laboratory for help and support.

\section{Authorship Contributions}

Participated in research design: Rimoldi, Dasgupta.

Contributed new reagents or analytic tools: Friedman, Brown, Nolan.

Wrote or contributed to the writing of the manuscript: Miles, Akers, Colclough, Rimoldi, Friedman, Brown, Nolan, Valentovic, Seidler, Dasgupta.

\section{References}

Appendino G, De Petrocellis L, Trevisani M, Minassi A, Daddario N, Moriello AS, Gazzieri D, Ligresti A, Campi B, Fontana G, et al. (2005) Development of the first ultra-potent "capsaicinoid" agonist at transient receptor potential vanilloid type 1 (TRPV1) channels and its therapeutic potential. J Pharmacol Exp Ther $\mathbf{3 1 2}$ $561-570$

Appendino G, Minassi A, Morello AS, De Petrocellis L, and Di Marzo V (2002) NAcylvanillamides: development of an expeditious synthesis and discovery of new acyl templates for powerful activation of the vanilloid receptor. J Med Chem 45:3739-3745.

Arzuman L, Beale P, Yu JQ, and Huq F (2016) Synthesis of tris(quinoline)monochloroplatinum(II) chloride and its activity alone and in combination with capsaicin and curcumin in human ovarian cancer cell lines. Anticancer Res 36:2809-2818.

Athanasiou A, Smith PA, Vakilpour S, Kumaran NM, Turner AE, Bagiokou D, Layfield R, Ray DE, Westwell AD, Alexander SP, et al. (2007) Vanilloid receptor agonists and antagonists are mitochondrial inhibitors: how vanilloids cause nonvanilloid receptor mediated cell death. Biochem Biophys Res Commun 354:50-55.

Basith S, Cui M, Hong S, and Choi S (2016) Harnessing the therapeutic potential of capsaicin and its analogues in pain and other diseases. Molecules 21:1-28.

Bode AM and Dong Z (2011) The two faces of capsaicin. Cancer Res 71:2809-2814.

Brown DC (2016) Resiniferatoxin: the evolution of the "Molecular Scalpel" for chronic pain relief. Pharmaceuticals (Basel) 9:47.

Carnevale V and Rohacs T (2016) TRPV1: a target for rational drug design. Pharmaceuticals (Basel) 9:pii:E52.

Caterina MJ, Schumacher MA, Tominaga M, Rosen TA, Levine JD, and Julius D (1997) The capsaicin receptor: a heat-activated ion channel in the pain pathway. Nature 389:816-824.

Chapa-Oliver AM and Mejía-Teniente L (2016) Capsaicin: from plants to a cancersuppressing agent. Molecules 21:E931.

Chen J, Luan Y, Yu R, Zhang Z, Zhang J, and Wang W (2014) Transient receptor potential (TRP) channels, promising potential diagnostic and therapeutic tools for cancer. Biosci Trends 8:1-10.

Chen MC, Yu CH, Wang SW, Pu HF, Kan SF, Lin LC, Chi CW, Ho LL, Lee CH, and Wang PS (2010) Anti-proliferative effects of evodiamine on human thyroid cancer cell line ARO. J Cell Biochem 110:1495-1503.

Chen TC, Chien CC, Wu MS, and Chen YC (2016) Evodiamine from Evodia rutaecarpa induces apoptosis via activation of JNK and PERK in human ovarian cancer cells. Phytomedicine 23:68-78.

Cho S-C, Lee H, and Choi B (2017) An updated review on molecular mechanisms underlying the anticancer effects of capsaicin. Food Sci Biotechnol 26:1-13.

Clark R and Lee SH (2016) Anticancer properties of capsaicin against human cancer. Anticancer Res 36:837-843.

Damião MC, Pasqualoto KF, Ferreira AK, Teixeira SF, Azevedo RA, Barbuto JA, Palace-Berl F, Franchi-Junior GC, Nowill AE, Tavares MT, et al. (2014) Novel capsaicin analogues as potential anticancer agents: synthesis, biological evaluation, and in silico approach. Arch Pharm (Weinheim) 347:885-895.

De Lago E, Gustafsson SB, Fernández-Ruiz J, Nilsson J, Jacobsson SO, and Fowler CJ (2006) Acyl-based anandamide uptake inhibitors cause rapid toxicity to C6 glioma cells at pharmacologically relevant concentrations. J Neurochem 99 677-688.

De Petrocellis L, Bisogno T, Davis JB, Pertwee RG, and Di Marzo V (2000) Overlap between the ligand recognition properties of the anandamide transporter and the VR1 vanilloid receptor: inhibitors of anandamide uptake with negligible capsaicinlike activity. FEBS Lett 483:52-56.

De Petrocellis L, Schiano Moriello A, Fontana G, Sacchetti A, Passarella D, Appendino G, and Di Marzo V (2014) Effect of chirality and lipophilicity in the functional activity of evodiamine and its analogues at TRPV1 channels. Br J Pharmacol 171: $2608-2620$

de-Sá-Júnior PL, Pasqualoto KF, Ferreira AK, Tavares MT, Damião MC, de Azevedo RA, Câmara DA, Pereira A, de Souza DM, and Parise Filho R (2013) RPF101, a new capsaicin-like analogue, disrupts the microtubule network accompanied by arrest in the G2/M phase, inducing apoptosis and mitotic catastrophe in the MCF-7 breast cancer cells. Toxicol Appl Pharmacol 266:385-398.

Díaz-Laviada I and Rodríguez-Henche N (2014) The potential antitumor effects of capsaicin. Prog Drug Res 68:181-208.

Di Marzo V, Griffin G, De Petrocellis L, Brandi I, Bisogno T, Williams W, Grier MC, Kulasegram S, Mahadevan A, Razdan RK, et al. (2002) A structure/activity relationship study on arvanil, an endocannabinoid and vanilloid hybrid. J Pharmacol Exp Ther 300:984-991.

Di Marzo V, Melck D, De Petrocellis L, and Bisogno T (2000) Cannabimimetic fatty acid derivatives in cancer and inflammation. Prostaglandins Other Lipid Mediat 61:43-61.

Drewes AM, Schipper KP, Dimcevski G, Petersen P, Gregersen H, Funch-Jensen P, and Arendt-Nielsen L (2003) Gut pain and hyperalgesia induced by capsaicin: a human experimental model. Pain 104:333-341.
Du J, Wang XF, Zhou QM, Zhang TL, Lu YY, Zhang H, and Su SB (2013) Evodiamine induces apoptosis and inhibits metastasis in MDA-MB-231 human breast cancer cells in vitro and in vivo. Oncol Rep 30:685-694.

Elokely K, Velisetty P, Delemotte L, Palovcak E, Klein ML, Rohacs T, and Carnevale V (2016) Understanding TRPV1 activation by ligands: insights from the binding modes of capsaicin and resiniferatoxin. Proc Natl Acad Sci USA 113:E137-E145.

Evangelista S (2015) Novel therapeutics in the field of capsaicin and pain. Expert Rev Clin Pharmacol 8:373-375.

Fan X, Zhu JY, Sun Y, Luo L, Yan J, Yang X, Yu J, Tang WQ, Ma W, and Liang HP (2017) Evodiamine inhibits zymosan-induced inflammation in vitro and in vivo: inactivation of $\mathrm{NF}-\kappa \mathrm{B}$ by inhibiting $\mathrm{I}_{\kappa} \mathrm{B} \alpha$ phosphorylation. Inflammation 40: 1012-1027.

Fang C, Zhang J, Qi D, Fan X, Luo J, Liu L, and Tan Q (2014) Evodiamine induces $\mathrm{G} 2 / \mathrm{M}$ arrest and apoptosis via mitochondrial and endoplasmic reticulum pathways in H446 and H1688 human small-cell lung cancer cells. PLoS One 9:e115204.

Farfariello V, Liberati S, Morelli MB, Tomassoni D, Santoni M, Nabissi M, Giannantoni A, Santoni G, and Amantini C (2014) Resiniferatoxin induces death of bladder cancer cells associated with mitochondrial dysfunction and reduces tumor growth in a xenograft mouse model. Chem Biol Interact 224:128-135.

Fernandes ES, Cerqueira AR, Soares AG, and Costa SK (2016) Capsaicin and its role in chronic diseases. Adv Exp Med Biol 929:91-125.

Ferreira AK, Tavares MT, Pasqualoto KF, de Azevedo RA, Teixeira SF, FerreiraJunior WA, Bertin AM, de-Sá-Junior PL, Barbuto JA, Figueiredo CR, et al. (2015) RPF151, a novel capsaicin-like analogue: in vitro studies and in vivo preclinical antitumor evaluation in a breast cancer model. Tumour Biol 36:7251-7267.

Frey MR, Clark JA, Bateman NW, Kazanietz MG, Black AR, and Black JD (2004) Cell cycle- and protein kinase C-specific effects of resiniferatoxin and resiniferonol 9,13,14-ortho-phenylacetate in intestinal epithelial cells. Biochem Pharmacol 67:1873-1886.

Friedman JR, Perry HE, Brown KC, Gao Y, Lin J, Stevenson CD, Hurley JD, Nolan NA, Akers AT, Chen YC, et al. (2017) Capsaicin synergizes with camptothecin to induce increased apoptosis in human small cell lung cancers via the calpain pathway. Biochem Pharmacol 129:54-66.

Gavaraskar K, Dhulap S, and Hirwani RR (2015) Therapeutic and cosmetic applications of evodiamine and its derivatives-a patent review. Fitoterapia 106:22-35

Glaser ST, Abumrad NA, Fatade F, Kaczocha M, Studholme KM, and Deutsch DG (2003) Evidence against the presence of an anandamide transporter. Proc Natl Acad Sci USA 100:4269-4274.

Gonzales CB, Kirma NB, De La Chapa JJ, Chen R, Henry MA, Luo S, and Hargreaves KM (2014) Vanilloids induce oral cancer apoptosis independent of TRPV1. Oral Oncology 50:437-447.

Guo H, Liu D, Gao B, Zhang X, You M, Ren H, Zhang H, Santos HA, and Xu F (2016) Antiproliferative activity and cellular uptake of evodiamine and rutaecarpine based on 3D tumor models. Molecules 21:E954.

Halme M, Pesonen M, Salo H, Söderström M, Pasanen M, Vähäkangas K, and Vanninen P (2016) Comparison of in vitro metabolism and cytotoxicity of capsaicin and dihydrocapsaicin. J Chromatogr B Analyt Technol Biomed Life Sci 1009-1010:17-24.

Hammer J (2006) Effect of repeated capsaicin ingestion on intestinal chemosensation and mechanosensation. Aliment Pharmacol Ther 24:679-686.

Han S, Woo JK, Jung Y, Jeong D, Kang M, Yoo YJ, Lee H, Oh SH, Ryu JH, and Kim WY (2016) Evodiamine selectively targets cancer stem-like cells through the p53p21-Rb pathway. Biochem Biophys Res Commun 469:1153-1158.

Hartel M, di Mola FF, Selvaggi F, Mascetta G, Wente MN, Felix K, Giese NA, Hinz U, Di Sebastiano P, Büchler MW, et al. (2006) Vanilloids in pancreatic cancer: potential for chemotherapy and pain management. Gut 55:519-528.

Hong YH, Lee WJ, Lee SH, Son JK, Kim HL, Nam JM, Kwon Y, and Jahng Y (2010) Synthesis and biological properties of benzo-annulated rutaecarpines. Biol Pharm Bull 33:1704-1709.

Hu C, Gao X, Han Y, Guo Q, Zhang K, Liu M, Wang Y, and Wang J (2016) Evodiamine sensitizes BGC-823 gastric cancer cells to radiotherapy in vitro and in vivo. Mol Med Rep 14:413-419.

Huang J, Chen ZH, Ren CM, Wang DX, Yuan SX, Wu QX, Chen QZ, Zeng YH, Shao $\mathrm{Y}, \mathrm{Li} \mathrm{Y}$, et al. (2015) Antiproliferation effect of evodiamine in human colon cancer cells is associated with IGF-1/HIF-1 $\alpha$ downregulation. Oncol Rep 34:3203-3211.

Huang JK, Cheng HH, Huang CJ, Kuo CC, Chen WC, Liu SI, Hsu SS, Chang HT, Lu YC, Tseng LL, et al. (2006) Effect of capsazepine on cytosolic $\mathrm{Ca}(2+)$ levels and proliferation of human prostate cancer cells. Toxicol In Vitro 20:567-574.

Huang XF, Xue JY, Jiang AQ, and Zhu HL (2013) Capsaicin and its analogues: structure-activity relationship study. Curr Med Chem 20:2661-2672.

Huh HC, Lee SY, Lee SK, Park NH, and Han IS (2011) Capsaicin induces apoptosis of cisplatin-resistant stomach cancer cells by causing degradation of cisplatininducible Aurora-A protein. Nutr Cancer 63:1095-1103.

Hurley JD, Akers AT, Friedman JR, Nolan NA, Brown KC, and Dasgupta P (2017) Non-pungent long chain capsaicin-analogs arvanil and olvanil display better antiinvasive activity than capsaicin in human small cell lung cancers. Cell Adh Migr 11:80-97.

Iadarola MJ and Gonnella GL (2013) Resiniferatoxin for pain treatment: an interventional approach to personalized pain medicine. Open Pain J 6:95-107.

Ivanova B and Spiteller M (2014) Evodiamine and rutaecarpine alkaloids as highly selective transient receptor potential vanilloid 1 agonists. Int J Biol Macromol 65: 314-324

Kan SF, Yu CH, Pu HF, Hsu JM, Chen MJ, and Wang PS (2007) Anti-proliferative effects of evodiamine on human prostate cancer cell lines DU145 and PC3. J Cell Biochem 101:44-56.

Khan M, Bi Y, Qazi JI, Fan L, and Gao H (2015a) Evodiamine sensitizes U87 glioblastoma cells to TRAIL via the death receptor pathway. Mol Med Rep 11:257-262.

Khan M, Maryam A, Mehmood T, Zhang Y, and Ma T (2015b) Enhancing activity of anticancer drugs in multidrug resistant tumors by modulating P-glycoprotein through dietary nutraceuticals. Asian Pac J Cancer Prev 16:6831-6839. 
Kobata K, Saito K, Tate H, Nashimoto A, Okuda H, Takemura I, Miyakawa K, Takahashi M, Iwai K, and Watanabe T (2010) Long-chain N-vanillyl-acylamides from capsicum oleoresin. J Agric Food Chem 58:3627-3631.

Lau JK, Brown KC, Dom AM, and Dasgupta P (2012) Capsaicin: Potential Applications in Cancer Therapy, Bentham Press, London.

Lau JK, Brown KC, Dom AM, Witte TR, Thornhill BA, Crabtree CM, Perry HE, Brown JM, Ball JG, Creel RG, et al. (2014) Capsaicin induces apoptosis in human small cell lung cancer via the TRPV6 receptor and the calpain pathway. Apoptosis 19:1190-1201.

Lee JH, Kim C, Baek SH, Ko JH, Lee SG, Yang WM, Um JY, Sethi G, and Ahn KS (2017) Capsazepine inhibits JAK/STAT3 signaling, tumor growth, and cell survival in prostate cancer. Oncotarget 8:17700-17711.

Lee TJ, Kim EJ, Kim S, Jung EM, Park JW, Jeong SH, Park SE, Yoo YH, and Kwon TK (2006) Caspase-dependent and caspase-independent apoptosis induced by evodiamine in human leukemic U937 cells. Mol Cancer Ther 5:2398-2407.

Lee YC, Lee CH, Tsai HP, An HW, Lee CM, Wu JC, Chen CS, Huang SH, Hwang J, Cheng KT, et al. (2015) Targeting of topoisomerase I for prognoses and therapeutics of camptothecin-resistant ovarian cancer. PLoS One 10:e0132579.

Lee YH, Im SA, Kim JW, and Lee CK (2016) Vanilloid receptor 1 agonists, capsaicin and resiniferatoxin, enhance $\mathrm{MHC}$ class I-restricted viral antigen presentation in virus-infected dendritic cells. Immune Netw 16:233-241.

Lewinska A, Chochrek P, Smolag K, Rawska E, and Wnuk M (2015) Oxidant-based anticancer activity of a novel synthetic analogue of capsaicin, capsaicin epoxide. Redox Rep 20:116-125.

Li W and Moore BM, II (2014) The effect of Arvanil on prostate cancer cells studied by whole cell high resolution magic angle spinning NMR. Mod Chem Appl 2:119-123.

Li-Weber M (2013) Targeting apoptosis pathways in cancer by Chinese medicine. Cancer Lett 332:304-312.

Li YL, Pan YN, Wu WJ, Mao SY, Sun J, Zhao YM, Dong JY, Zhang DY, Pan JP, Zhang C, et al. (2016) Evodiamine induces apoptosis and enhances apoptotic effects of erlotinib in wild-type EGFR NSCLC cells via S6K1-mediated Mcl-1 inhibition. Med Oncol 33:16.

Liao CH, Pan SL, Guh JH, Chang YL, Pai HC, Lin CH, and Teng CM (2005) Antitumor mechanism of evodiamine, a constituent from Chinese herb Evodiae fructus, in human multiple-drug resistant breast cancer NCI/ADR-RES cells in vitro and in vivo. Carcinogenesis 26:968-975.

Liu AJ, Wang SH, Chen KC, Kuei HP, Shih YL, Hou SY, Chiu WT, Hsiao SH, and Shih CM (2013a) Evodiamine, a plant alkaloid, induces calcium/JNK-mediated autophagy and calcium/mitochondria-mediated apoptosis in human glioblastoma cells. Chem Biol Interact 205:20-28.

Liu AJ, Wang SH, Hou SY, Lin CJ, Chiu WT, Hsiao SH, Chen TH, and Shih CM (2013b) Evodiamine induces transient receptor potential vanilloid-1-mediated protective autophagy in U87-MG astrocytes. Evid Based Complement Alternat Med 2013:354840

Liu H, Huang C, Wu L, and Wen B (2016) Effect of evodiamine and berberine on miR429 as an oncogene in human colorectal cancer. Onco Targets Ther 9:4121-4127.

Luviano A, Aguiñiga-Sánchez I, Demare P, Tiburcio R, Ledesma-Martínez E, Santiago-Osorio E, and Regla I (2014) Antineoplastic activity of rinvanil and phenylacetylrinvanil in leukaemia cell lines. Oncol Lett 7:1651-1656.

Macho A, Lucena C, Sancho R, Daddario N, Minassi A, Muñoz E, and Appendino G (2003) Non-pungent capsaicinoids from sweet pepper synthesis and evaluation of the chemopreventive and anticancer potential. Eur $J$ Nutr 42:2-9.

Melck D, Bisogno T, De Petrocellis L, Chuang H, Julius D, Bifulco M, and Di Marzo V (1999) Unsaturated long-chain N-acyl-vanillyl-amides (N-AVAMs): vanilloid receptor ligands that inhibit anandamide-facilitated transport and bind to CB1 cannabinoid receptors. Biochem Biophys Res Commun 262:275-284.

Meng ZJ, Wu N, Liu Y, Shu KJ, Zou X, Zhang RX, Pi CJ, He BC, Ke ZY, Chen L, et al. (2015) Evodiamine inhibits the proliferation of human osteosarcoma cells by blocking PI3K/Akt signaling. Oncol Rep 34:1388-1396.

Min JK, Han KY, Kim EC, Kim YM, Lee SW, Kim OH, Kim KW, Gho YS, and Kwon YG (2004) Capsaicin inhibits in vitro and in vivo angiogenesis. Cancer Res 64: $644-651$

Naziroğlu M, Çiğ B, Blum W, Vizler C, Buhala A, Marton A, Katona R, Jósvay K, Schwaller B, Oláh Z, et al. (2017) Targeting breast cancer cells by MRS1477, a positive allosteric modulator of TRPV1 channels. PLoS One 12:e0179950.

Nishino K, Tanamachi K, Nakanishi Y, Ide S, Kojima S, Tanuma S, and Tsukimoto M (2016) Radiosensitizing effect of TRPV1 channel inhibitors in cancer cells. Biol Pharm Bull 39:1224-1230

O'Neill J, Brock C, Olesen AE, Andresen T, Nilsson M, and Dickenson AH (2012) Unravelling the mystery of capsaicin: a tool to understand and treat pain. Pharmacol Rev 64:939-971.

Ogasawara M, Matsubara T, and Suzuki H (2001) Inhibitory effects of evodiamine on in vitro invasion and experimental lung metastasis of murine colon cancer cells. Biol Pharm Bull 24:917-920.

Ogasawara M, Matsunaga T, Takahashi S, Saiki I, and Suzuki H (2002) Antiinvasive and metastatic activities of evodiamine. Biol Pharm Bull 25:1491-1493.

Oh SH, Kim YS, Lim SC, Hou YF, Chang IY, and You HJ (2008) Dihydrocapsaicin (DHC), a saturated structural analog of capsaicin, induces autophagy in human cancer cells in a catalase-regulated manner. Autophagy 4:1009-1019.

$\mathrm{Oh}$ SH and Lim SC (2009) Endoplasmic reticulum stress-mediated autophagy/ apoptosis induced by capsaicin (8-methyl-N-vanillyl-6-nonenamide) and dihydrocapsaicin is regulated by the extent of c-Jun NH2-terminal kinase/extracellular signal-regulated kinase activation in WI38 lung epithelial fibroblast cells. $J$ Pharmacol Exp Ther 329:112-122.

Pan X, Hartley JM, Hartley JA, White KN, Wang Z, and Bligh SW (2012) Evodiamine, a dual catalytic inhibitor of type I and II topoisomerases, exhibits enhanced inhibition against camptothecin resistant cells. Phytomedicine 19:618-624.

Pearce LV, Petukhov PA, Szabo T, Kedei N, Bizik F, Kozikowski AP, and Blumberg PM (2004) Evodiamine functions as an agonist for the vanilloid receptor TRPV1. Org Biomol Chem 2:2281-2286.
Peng X, Zhang Q, Zeng Y, Li J, Wang L, and Ai P (2015) Evodiamine inhibits the migration and invasion of nasopharyngeal carcinoma cells in vitro via repressing MMP-2 expression. Cancer Chemother Pharmacol 76:1173-1184.

Pyun BJ, Choi S, Lee Y, Kim TW, Min JK, Kim Y, Kim BD, Kim JH, Kim TY, Kim YM, et al. (2008) Capsiate, a nonpungent capsaicin-like compound, inhibits angiogenesis and vascular permeability via a direct inhibition of Src kinase activity. Cancer Res 68:227-235.

Sachita K, Kim Y, Yu HJ, Cho SD, and Lee JS (2015) In vitro assessment of the anticancer potential of evodiamine in human oral cancer cell lines. Phytother Res 29:1145-1151.

Sánchez-Sánchez L, Alvarado-Sansininea JJ, Escobar ML, López-Muñoz H, HernándezVázquez JM, Monsalvo-Montiel I, Demare P, Regla I, and Weiss-Steider B (2015) Evaluation of the antitumour activity of Rinvanil and Phenylacetylrinvanil on the cervical cancer tumour cell lines HeLa, CaSKi and ViBo. Eur J Pharmacol 758:129-136.

Sancho R, de la Vega L, Appendino G, Di Marzo V, Macho A, and Munoz E (2003) The CB1/VR1 agonist arvanil induces apoptosis through an FADD/caspase-8 dependent pathway. Br J Pharmacol 140:1035-1044

Schneider DJ, Seuß-Baum I, and Schlich E (2014) Comparison between chemical senses thresholds for capsaicin and dihydrocapsaicin in aqueous solutions and identification of the area of burning sensatation. Adv J Food Sci Technol 6: $36-41$

Shen H, Zhao S, Xu Z, Zhu L, Han Y, and Ye J (2015) Evodiamine inhibits proliferation and induces apoptosis in gastric cancer cells. Oncol Lett 10:367-371.

Shi CS, Li JM, Chin CC, Kuo YH, Lee YR, and Huang YC (2017) Evodiamine induces cell growth arrest, apoptosis and suppresses tumorigenesis in human urothelial cell carcinoma cells. Anticancer Res 37:1149-1159.

Shi L, Yang F, Luo F, Liu Y, Zhang F, Zou M, and Liu Q (2016) Evodiamine exerts anti-tumor effects against hepatocellular carcinoma through inhibiting $\beta$-cateninmediated angiogenesis. Tumour Biol 37:12791-12803.

Silva R, Vilas-Boas V, Carmo H, Dinis-Oliveira RJ, Carvalho F, de Lourdes Bastos M, and Remião F (2015) Modulation of P-glycoprotein efflux pump: induction and activation as a therapeutic strategy. Pharmacol Ther 149:1-123.

Song S, Chen Z, Li S, Huang Y, Wan Y, and Song H (2013) Design, synthesis and evaluation of N13-substituted evodiamine derivatives against human cancer cell lines. Molecules 18:15750-15768.

Srinivasan K (2016) Biological activities of red pepper (Capsicum annuum) and its pungent principle capsaicin: a review. Crit Rev Food Sci Nutr 56:1488-1500.

Stock K, Kumar J, Synowitz M, Petrosino S, Imperatore R, Smith ES, Wend P, Purfürst B, Nuber UA, Gurok U, et al. (2012) Neural precursor cells induce cell death of high-grade astrocytomas through stimulation of TRPV1. Nat Med 18: $1232-1238$

Sui H, Zhou LH, Zhang YL, Huang JP, Liu X, Ji Q, Fu XL, Wen HT, Chen ZS, Deng WL, et al. (2016) Evodiamine suppresses ABCG2 mediated drug resistance by inhibiting p50/p65 NF-кB pathway in colorectal cancer. J Cell Biochem 117: 1471-1481.

Teng HP, Huang CJ, Yeh JH, Hsu SS, Lo YK, Cheng JS, Cheng HH, Chen JS, Jiann BP, Chang HT, et al. (2004) Capsazepine elevates intracellular Ca2+ in human osteosarcoma cells, questioning its selectivity as a vanilloid receptor antagonist. Life Sci 75:2515-2526.

Thomas KC, Ethirajan M, Shahrokh K, Sun H, Lee J, Cheatham TE, III, Yost GS, and Reilly CA (2011) Structure-activity relationship of capsaicin analogs and transient receptor potential vanilloid 1-mediated human lung epithelial cell toxicity. J Pharmacol Exp Ther 337:400-410.

Thomas KC, Roberts JK, Deering-Rice CE, Romero EG, Dull RO, Lee J, Yost GS, and Reilly CA (2012) Contributions of TRPV1, endovanilloids, and endoplasmic reticulum stress in lung cell death in vitro and lung injury. Am J Physiol Lung Cell Mol Physiol 302:L111-L119.

Thomas KC, Sabnis AS, Johansen ME, Lanza DL, Moos PJ, Yost GS, and Reilly CA (2007) Transient receptor potential vanilloid 1 agonists cause endoplasmic reticulum stress and cell death in human lung cells. J Pharmacol Exp Ther 321: 830-838.

Tuoya BN, Baba N, Shimoishi Y, Murata Y, Tada M, Koseki M, and Takahata K (2006) Apoptosis induction by dohevanil, a DHA substitutive analog of capsaicin, in MCF-7 cells. Life Sci 78:1515-1519.

Vendrely V, Peuchant E, Buscail E, Moranvillier I, Rousseau B, Bedel A, Brillac A, de Verneuil H, Moreau-Gaudry F, and Dabernat S (2017) Resveratrol and capsaicin used together as food complements reduce tumor growth and rescue full efficiency of low dose gemcitabine in a pancreatic cancer model. Cancer Lett $\mathbf{3 9 0}$ 91-102.

Vercelli C, Barbero R, Cuniberti B, Racca S, Abbadessa G, Piccione F, and Re G (2014) Transient receptor potential vanilloid 1 expression and functionality in mcf7 cells: a preliminary investigation. J Breast Cancer 17:332-338.

Wang S, Fang K, Dong G, Chen S, Liu N, Miao Z, Yao J, Li J, Zhang W, and Sheng C (2015) Scaffold diversity inspired by the natural product evodiamine: discovery of highly potent and multitargeting antitumor agents. J Med Chem 58:6678-6696.

Wang S, Wang L, Shi Z, Zhong Z, Chen M, and Wang Y (2014) Evodiamine synergizes with doxorubicin in the treatment of chemoresistant human breast cancer without inhibiting P-glycoprotein. PLoS One 9:e97512.

Wang S, Yamamoto S, Kogure Y, Zhang W, Noguchi K, and Dai Y (2016) Partial activation and inhibition of TRPV1 channels by evodiamine and rutaecarpine, two major components of the fruits of evodia rutaecarpa. J Nat Prod 79:1225-1230.

Wang T, Wang Y, and Yamashita H (2009) Evodiamine inhibits adipogenesis via the EGFR-PKCalpha-ERK signaling pathway. FEBS Lett 583:3655-3659.

Wang Z, Sun L, Yu H, Zhang Y, Gong W, Jin H, Zhang L, and Liang H (2012) Binding mode pediction of evodiamine within vanilloid receptor TRPV1. Int J Mol Sci 13: 8958-8969.

Watanabe T, Ohnuki K, and Kobata K (2011) Studies on the metabolism and toxicology of emerging capsinoids. Expert Opin Drug Metab Toxicol 7:533-542.

Wei L, Jin X, Cao Z, and Li W (2016) [Evodiamine induces extrinsic and intrinsic apoptosis of ovarian cancer cells via the mitogen-activated protein kinase/ 
phosphatidylinositol-3-kinase/protein kinase B signaling pathways]. J Tradit Chin Med 36:353-359.

Wei WT, Chen H, Wang ZH, Ni ZL, Liu HB, Tong HF, Guo HC, Liu DL, and Lin SZ (2012) Enhanced antitumor efficacy of gemcitabine by evodiamine on pancreatic cancer via regulating PI3K/Akt pathway. Int J Biol Sci 8:1-14.

Wen Z, Feng S, Wei L, Wang Z, Hong D, and Wang Q (2015) Evodiamine, a novel inhibitor of the Wnt pathway, inhibits the self-renewal of gastric cancer stem cells. Int $J$ Mol Med 36:1657-1663.

Wu WS, Chien CC, Chen YC, and Chiu WT (2016) Protein kinase RNA-like endoplasmic reticulum kinase-mediated Bcl-2 protein phosphorylation contributes to evodiamineinduced apoptosis of human renal cell carcinoma cells. PLoS One 11:e0160484.

Wu WS, Chien CC, Liu KH, Chen YC, and Chiu WT (2017) Evodiamine prevents glioma growth, induces glioblastoma cell apoptosis and cell cycle arrest through JNK activation. Am J Chin Med 45:879-899.

Xie L, Xiang GH, Tang T, Tang Y, Zhao LY, Liu D, Zhang YR, Tang JT, Zhou S, and Wu DH (2016) Capsaicin and dihydrocapsaicin induce apoptosis in human glioma cells via ROS and Ca2+-mediated mitochondrial pathway. Mol Med Rep 14: $4198-4208$

Yang F, Shi L, Liang T, Ji L, Zhang G, Shen Y, Zhu F, and Xu L (2017) Anti-tumor effect of evodiamine by inducing Akt-mediated apoptosis in hepatocellular carcinoma. Biochem Biophys Res Commun 485:54-61.

Yang J, Cai X, Lu W, Hu C, Xu X, Yu Q, and Cao P (2013) Evodiamine inhibits STAT3 signaling by inducing phosphatase shatterproof 1 in hepatocellular carcinoma cells. Cancer Lett 328:243-251.

Yu H, Jin H, Gong W, Wang Z, and Liang H (2013) Pharmacological actions of multitarget-directed evodiamine. Molecules 18:1826-1843.
Yu H, Tu Y, Zhang C, Fan X, Wang X, Wang Z, and Liang H (2010) Evodiamine as a novel antagonist of aryl hydrocarbon receptor. Biochem Biophys Res Commun 402:94-98.

Zhang C, Fan X, Xu X, Yang X, Wang X, and Liang HP (2010) Evodiamine induces caspase-dependent apoptosis and $\mathrm{S}$ phase arrest in human colon lovo cells. Anticancer Drugs 21:766-776.

Zhao LC, Li J, Liao K, Luo N, Shi QQ, Feng ZQ, and Chen DL (2015) Evodiamine induces apoptosis and inhibits migration of HCT-116 human colorectal cancer cells. Int $J$ Mol Sci 16:27411-27421.

Zhong ZF, Tan W, Wang SP, Qiang WA, and Wang YT (2015) Anti-proliferative activity and cell cycle arrest induced by evodiamine on paclitaxel-sensitive and -resistant human ovarian cancer cells. Sci Rep 5:16415.

Zhu LH, Bi W, Liu XD, Li JF, Wu YY, Du BY, and Tan YH (2011) Induction of apoptosis by evodiamine involves both activation of mitotic arrest and mitotic slippage. Oncol Rep 26:1447-1455.

Ziglioli F, Frattini A, Maestroni U, Dinale F, Ciufifeda M, and Cortellini P (2009) Vanilloid-mediated apoptosis in prostate cancer cells through a TRPV-1 dependent and a TRPV-1-independent mechanism. Acta Biomed 80:13-20.

Zou Y, Qin X, Xiong H, Zhu F, Chen T, and Wu H (2015) Apoptosis of human nonsmall-cell lung cancer A549 cells triggered by evodiamine through MTDHdependent signaling pathway. Tumour Biol 36:5187-5193.

$\overline{\text { Address correspondence to: Dr. Piyali Dasgupta, Joan C. Edwards School }}$ of Medicine, Marshall University, 1700 3rd Avenue, Huntington, WV 25705. E-mail: dasgupta@marshall.edu 